\title{
A desigual dade como meio de vida: educação e classe social na América Latina
}

Nelly P. Stromquist

Palavras-chave desigual dades educacionais; classesocial; qual idadedo ensino; acesso à escola; políticas governamentais específicas; América Latina.

\section{Resumo}

A desigual dade na educação é lamentada pelo governo e pela sociedade. A pesar disso, as diferenças de acesso e de qual idade continuam sem um questionamento eficaz, pois a isto são acrescentadas a distribuição das escolas em privadas e particulares e a decadência da escol a rural quanto ao número de horas-aula, preparação docente einfraestrutura. Recentes estatísticas de âmbito regional sobre o efeito combinado de classe social e gênero indicam que as mulheres de qual quer idade escolar e pertencentes a qual quer estrato socioeconômi co sofrem desvantagem no acesso à escol a em rel ação aos homens. As medi das compensatórias para di mi nuir a desi gual dade são míni mas na regi ão. Outros fatores, inclusive o racismo e model os de desenvolvimento supostamente apolíticos, mantêm-sefortemente arrai gados nas políticas educacionais e aténo comportamento latino-americano.

\section{Introdução}

Com o passar do tempo, os sistemas educacionais vieram a ser identificados tanto na retórica governamental quanto na popular - como o fator mais importantepara a democratização da sociedade. Empiricamente, ébem sabido que, embora a educação promovaa mobilidade social, ela tende, também, a reproduzir a distribuição social de classes, em qual quer dada sociedade. Essa estranha coexistência entre inclusão eexclusão merececuidadoso escrutínio. Uma região geográfica que se prestaa essetipo de exameéa América Latina, que dispõede um sistema educacional público dehá muito estabel ecido eondeas diferenças econômicas entre a população são das mais altas do mundo.

Comparada a outras regi ões em desenvolvimento, a América Latina exibeos mais al tos índices de matrícula em todos os níveis da educação (Unesco, 1999). Para o ensi no fundamental, relatórios oficiais reveIam haver uma média líquida de matrícula da ordem de $93 \%$. O ensino médi o matricula menos crianças, mas ainda assimapresenta uma média líquida de $63 \%$, mais elevada que a de outras regiões. No contexto da América Latina, o fato de $37 \%$ dajuventude não se beneficiar da escola secundária é pesaroso, uma vez que, de acordo com estudos da Cepal (1994, p. 31) "necessitase de dez anos de escolaridade, e em muitos casos o secundário completo, para se atingir rendimentos acima da linha da pobreza". Em nível universitário, as taxas departicipação são comparativamenteal tas, também, atingindo a média de $19 \%$.

As estatísticas nacionais da educação disponíveis, porém, nada nos dizem quanto àfreqüência (Puryear, 1995). É perfeitamente 
possível queas crianças matriculem-seenão freqüentem a escol a com a regul aridadenecessária para completar um grau com sucesso. Dados derivados de pesquisas domiciliares, efetuadas em quatros países latinoamericanos, revelam um número muito mai or de crianças fora da escola (quer temporária ou permanentemente), que o número líquido de matrículas sugere para a escol a fundamental, em três dos quatro países: Peru, Colômbia e Haiti (UIS 2003). Estatísticas para com a matrícula, freqüência e concl usão, embora necessárias, nada nos informam, porém, quanto à qual idade da educação recebida. Em muitas escolas públicas da região, os alunos estão recebendo entre três e quatro horas de escolaridade por dia, isso vindo a refletir-se no total de horas de instrução por ano, que chega a 692 horas no Paraguai, 732 no Uruguai, 800 no Brasil , 810 na Argentina e 925 no Chile (OECD, 2000). ${ }^{1}$

No tocanteà matrícula, são pequenas as diferenças entre homens e mulheres na América Latina e, em al guns países, mais mulheres parecem beneficiar-se da escola secundária que homens, embora, novamente, as diferenças sejam leves (Unesco, 1999). A distribuição de educação por riqueza permanecealtamentedistorcida, com o grupo dos $20 \%$ mais pobres al cançando quatro anos deescolaridade, em contrastecom o dos $20 \%$ mais ricos, que chega a 10 anos deescolaridade. (Rodríguez, 2002). ${ }^{2}$

Embora haja grande diversi dadeentre os países da América Latina, também há al guns fortes pontos em comum. Um deles éo passado colonial (não tão recente, mas ainda bem visível) que imbuiu a cultura da noção de que ser branco é mel hor do que ser mestiço, índio ou negro - uma norma difusa, que não contribuiu para a criação de respei to significativo pel a diversidade étnica. Outro ponto em comum é o discurso público altamenteentusiástico, às vezes até declarado em políticas públicas, desaprovando as desigual dades sociais, mas com uma prática que caminha mui to vagarosamenteao combatêlas.

Neste trabal ho, resenho a distribuição da escolaridade na América Latina, observando quem recebe o quê e por quê. Procuro mostrar que, apesar da ampliação do acesso a todos os níveis da educação, e apesar das melhores taxas de conclusão, as vantagens fundamentais de certos grupos sobre outros e de certas regi ões sobre outras permanecem basicamentenão modificadas. Para fazêllo, descrevo as condições deescolaridade na região, examino as definições de igual dade/desi gual dadee pobre$z a$, resenho as formas de desigual dade na educação e discuto políticas governamentais para com a educação esua distribuição. Termino por avaliar o futuro da desigualdade na educação da América Latina.

\section{A natureza ainda não reconhecida da pobreza}

A pobreza éuma força dinâmica, pois ela libera seu próprio el enco de recursos limitados e práticas opressoras, as quais, por sua vez, criam processos de exclusão e margi nal ização (Kabeer, 1998). Todos nós conhecemos diversas definições de pobreza, mas freqüentemente as acol hemos sem compreender total mente a sua validade. Uma de tais medi das é a definição de pobreza do Banco Mundial, como a de uma pessoa que vive com menos de dois dólares por diae, de extrema pobreza, para aquela vivendo com menos de um dólar por dia. Ainda assim, como observa Chossudovsky (1998), essa é uma medida arbitrária, que não se baseia em observação cui dadosa dos gastos de uma família, na vida real, com al imentação, moradia e serviços sociais e que, portanto, provavel mente, subestima as verdadeiras mani festações da pobreza. Além disso, essa medida reflete um padrão duplo, uma vez quese aplica apenas a países em desenvol vimento. Países industrializados constroem gabaritos mais precisos para aval iar a pobreza, rel acionando-a em níveis mínimos bem conhecidos de gastos domésticos para enfrentar as despesas essenciais em alimentação, vestuário, saúde, moradia e educação. Nada surpreendente no fato de os níveis oficiais de pobreza em países industrial izados serem muito mais al tos que a noção dos dois dólares por dia, mesmo quetal medida seja cal culada em termos de dólares com paridade de poder aquisitivo (PPA), partindo do pressuposto de que o poder deaquisi ção desses dólares seja igualmente comparável em todos os países. ${ }^{3}$

O PIB de países latino-americanos não vem crescendo tão rapidamentecomo aqueledediversos países asiáticos; no entanto, a região possui riquezas consideráveis. Mas tais riquezas são desigual mentedistribuídas. o Brasil, o país com o maior índice de

\footnotetext{
1 Estesdadostêmorigemnumprojeto quefocal izou um número seleto depaíses em desenvolvimento (incluindo os cinco países latino-americanos citados) eutilizou umgrupo maior deindicadores provenientes das estatísticas regulares daUnesco. $\mathrm{O}$ projetoestásendoconduzidoem conjunto pelaOECD epeloInstituto deEstatísticas daUnesco (UIS).

2 É umfenômeno deamplitude mundial queuma criançarica tenhauma probabilidademaior desematricularnumaescolaque uma criança pobre. Dados da Indonésia, do Paquistão, daÍndiaedo Nepal confirmamofato. NaÍndia, amédianacional dede sigual dadeédecercade 31 pontos percentuaisentrericosepobres, emborahajaumavariação entreestados quevai de $4,6 \%$ em Kerala, para $42 \%$ em Bihar (Filmer; Pritchett, 2000).

3 Osdólares deParidadedePoder Aquisitivo (PPA) são computa dos de modo que uma dada quantia nesse tipo de moeda corrente"possacomprar amesmacestademercadorias eserviçosemtodos os países" (OECD 2000, p. 144). Esteprocedimento, contudo, parecenãocaptar realidadeeconômicadediversos países.
} 
desigual dadederendas, apresenta uma mé dia de 33 para 1 entrea renda dos $20 \%$ mais ricos e os $20 \%$ mais pobres da população. Como ponto dereferência, podemos observar que, noJapão, o índice entre esses dois grupos opostos é de 4 para 1 (Larrain; Vergara, citados em Martinez, 2002). NaArgentina, onde havia uma classe média ampla, as disparidades de rendas cresceram entre 1988 e 1998, quando os $10 \%$ do segmento mais pobre da população, queganhava 18 vezes menos que o $10 \%$ mais ricos, passou a receber 24 vezes menos (Vior, 2001). Os segmentos mais pobres da popul ação se compõem das populações rurais deindígenas e denegros, contribuindo para reforçar os estereótipos sociais de que tais setores são menos competentes ou industriosos do que os grupos mais bem situados economicamente

A extensão das disparidades de rendas entre classe sociais, residências urbanas/rurais eas etnias, tem levado diversos governos e personal idades políticas a considerar que as desigual dades entre os sexos são de menor portenaAmérica Latina. A situação das mulheres pobres é, na real idade, muito séria, ainda assim o problema das disparidades entre os sexos não pode ser reduzido a uma questão de pobreza, apenas, pois inúmeras formas de subordinação e excl usão afetando as mulheres se infiltram entre todas as faixas de riqueza (Kabeer, 1996). Essa fal ta de consideração à questão homem-mulher, na A mérica Latina, é evidente, na ausência de uma anál ise entre as diferenças por sexo, nas mais recentes iniciativas regi onais de mai or porte para a educação, tais como a Declaração de Cochabamba e a Reunião de Cúpula das Américas (videStromquist, 2003).

\section{A definiç̧ão de igualdade}

Igual dadeem educação é um conceito com uma longa trajetória eevol ução correspondente. Refere-se, essencialmente, ao modo como um bem educacional é distribuído entre os membros de uma população. Existe uma ti pologia bem aceita para definir a igual dade educacional, dotandoa de quatro dimensões: igual dade de acesso (matrículas), igual dade de obtenção (também chamada desobrevivência), igualdade de produção (ou deal cance do aprendizado) e igualdade de resultados, ou o retorno decorrente da escolaridade (Farrell, 1992). Outros observadores (notavel mente Coleman, 1968) incluem também uma quinta dimensão, ou igual dade detratamento (ou acesso à boa qualidade de professores, materiais eexperiência educacional em geral ). Mais freqüentemente, definições deigual dade referem-seà distribuição imediata de recursos (acesso, professores einfraestrutura), e, em menor escal a, à obtenção e, em muito menor escala, ao al cance do aprendizado, à natureza da experiência educacional, a partir da perspectiva dos alunos, e os retornos decorrentes da escolaridade.

As medidas da distribuição educacional são obrigadas, é claro, a considerar o acesso à escolaridade pela forma de taxas de matrícula. Além disso, contudo, essas medidas têm de avaliar, no mínimo, outras condições relacionadas ao fornecimento, tais como a permanência do al uno na escola, a quantidade e qualidade de insumos educacionais básicos, professores, em particular, eo número ecaracterísticas das pessoas que atingem dados níveis de al cance educacional (Martinez, 2002). Estatísticas educacionais a este respeito ainda não se acham disponíveis para muitos países, especial mente aquel es mais pobres e em desenvol vimento. A América Latina também tem uma escassez de estatísticas educacionais referentes a questões quanto à quantidade e qual idade de insumos e resultados da educação. A maioria das discussões políticas sobre igual dade fica local izada no nível de acesso. Pouca consideração é dedicada às outras dimensões da igual dade, exceto que os objetivos atuais da iniciativa Educação para Todos (baseada na Declaração de Dacar, 2000) e os Objeti vos de Desenvolvimento do Milênio estão exigindo a conclusão do ensino fundamental . Mas, assim mesmo, este objetivo parece ser al go a ser al cançado em futuro distante, lá pelo ano 2015 (videUnesco, 2000).

O exame detal hado da trajetória da distribuição educacional no México nos últimos 40 anos, realizado por Martinez (2002), é bastante elucidativo. Martinez descobre que, embora a média de anos de escolarização esteja aumentando e os níveis de disparidade entre os estados mexicanos venham diminuindo desde 1970, a hierarquia educacional relativa dos estados permaneceu estável. Os estados mais pobres continuam a ter os níveis mais baixos de rendimento escolar eos estados mais ricos, 
os mais al tos. Além disso, as diferenças em investimentos educacionais, por estado, continuam sendo substanciais, tendo o México, DF, um coeficienteGini (quemede a desigual dadenuma escal a máxima de 1,0 ) de 0,25, eChiapas um coeficiente de 0,48. Uma vez que a desigual dade permanece concentrada nos mesmos estados pobres do passado, Martinez conclui que o progresso educacional émuito mais atribuível à expansão educacional geral do que as políticas compensatórias específicas para com os pobres - um comentário surpreendente, já queo M éxico se distingue por ter uma das mai s fortes políticas compensatórias para com a Educação na região latinoamericana. Martinez (2002, p. 426) afirma: "Se um país quiser melhorar seu nível médio de rendimento educacional, a meIhor estratégia será mel horar a educação das regiões mais pobres". ${ }^{4}$

\section{Formas de desigualdade na educação na América Latina}

\section{Escolas rurais com quadro de pessoal pobre e incompleto}

Indubitavelmente, na região latinoamericana, as mai ores formas de desigualdade na educação resi dem nas desigual dades entre os ambientes rurais e urbanos. Devendo-se, em parte, à distribuição bastante esparsa da população rural, mas em parte também à negl igência política, a cobertura proporcionada pela escol a pública nas áreas rurais ébastantelimitada. Crianças indígenas tendem a constituir o núcleo dos estudantes rurais, exceto no Brasil e na Colômbia, ondemuitas dessas crianças são de ascendência africana.

Muito poucos alunos indígenas podem freqüentar a escola na América Latina. Isso, em geral, fica bastante obscurecido nas estatísticas nacionai s. O estudo de Schmel kes (2000), porém, descobriu que, no México - país que conta com as mais desenvol vidas políticas indígenas na América Latina - , menos de $5 \%$ da população indígena emidadeescolar matriculou-seem escolas públicas no período 1997-1998.
Essa taxa muito limitada de matrículas reflete diversos fatores: a necessi dade paterna de contar com o trabal ho dos filhos, o ceticismo quanto à utilidade da escolarização formal no ambienterural, talvez. Um fator si gnificativo, porém, refereseà disponi bilidade educaci onal. Muitas escolas rurais na América Latina são incompletas, equivalendo a dizer que são escolas primárias que não cobrem todas as séries. Um estudo sobre escol as rurais no Peru descobriu que $90 \%$ dessas escolas operavam em sal as únicas e que $37 \%$ tinham apenas um professor, sugerindo um grandenúmero de escolas primárias incompletas (Montero; Tovar, 1999). Um estudo anterior, de 1997, baseado em um censo escolar e num inventário, feitos em centros educacionais, descobriu que $95 \%$ a 98\% das escolas primárias incompletas localizavam-se em áreas rurais (apud Iguiñiz; Dueñas, 1998). Aulas dadas, em geral, por um professor mal preparado, que, ainda por cima, tem de lidar com al unos fracos, em diversos graus e níveis, fazem das escolas rurais incompletas locais educaci onais muito desafiadores, onde as crianças recebem entre três a quatro anos de escolaridade. Dada a baixa qualidadedesua escolarização, em geral cristal izada em tempo limitado à tarefa, as crianças freqüentemente não atingem habilidades básicas de al fabetização, indo mais tarde juntar-se às filei ras de adultos com baixos níveis deal fabetização.

Um estudo etnográfico de duas escolas rurais nas montanhas do Peru (Hornberger, 1987) documentou cuidadosamente como o tempo das crianças na escola e em sala de aula era distribuído. Hornberger descobriu que, depois de descontar o tempo dedi cado a brincadeiras, a manter limpo o pátio e às outras atividades escolares não educacionais, o tempo em que os professores se ausentavam, etc., as crianças receberam o equival ente a 15 minutos diários de "tempo de aprendizado acadêmico" - claramente em quantidade insuficiente para desenvolver hábitos deleitura ou desenvol vimento cognitivo de alta ordem. Estudos como esse não vêm sendo replicados nos anos recentes e, considerando-se as condições ainda ruins das escolas e dos professores rurais, não seria de se espantar descobrir que pouco mudou.

\footnotetext{
4 Devesenotar queosindicadores disponíveisnemsempresão estáveis. Por exemplo, dadossobre os resultados educacionais no Méxiconão são congruentes. As estatísticas do OECD, para1998, referentesàfaixade25a64anos, revelam queo México tem um coeficienteGini dedesigualdade nos resultadosfinais, de 0,266, enquanto queMartinez (2002) usando uma faixa etária de 15 anos ou mais, relataum coeficienteGini dedesigual dadede0,35 paraoano 2000, umadisparidade quenão pareceexplicável pelas diferenças relativamenteleves emtempo eidades.
} 


\section{A oferta distinta de escolas públicas e particulares}

Outra forma importante de desigualdade em educação na regi ão da América Latina reside nas desigual dades entre escolas públicas e particulares. Tradicionalmente, e muito mais do que em outros países, as classes sociais superiores freqüentam escolas particulares. O desempenho das escolas particulares deeliteraramenteéinvestigado, mas é claro que as crianças que freqüentam tais escolas por seis horas por dia trazem para casa deveres extensos, lêem livros de al ta qual idade, têm amplo acesso nalnternet, eainda podem seempenhar em diversas atividades extracurriculares, logo desenvolvem uma vantagem educacional sobre crianças de escolas emeio ambientes menos bem dotados. Uma estimativa para as horas escolares no Peru descobriu que, nas escol as rurais, o tempo total izava 226 horas por ano em áreas rurais, 450 horas por ano em regiões urbanas pobres, e mil horas por ano em escolas particulares (Iguiñiz; Dueñas, 1998). Estatísticas apresentando cobertura, forma econteúdo quanto às escol as particulares na região são incompletas e, provavelmente, pouco confiáveis, pois nem todas as escol as particulares submetem registros detal hados ou verificados. Assim mesmo, é dentro desta forma de educação quea mai oria das futuras desigual dades sociais são construídas.

A análise de Schmelkes (2000), para com as escolas mexicanas, detectou dife renças substanciais no desempenho dealunos, dependendo do tipo de escola (quer pública ou particular, urbana ou rural, ou indígena). Ela descobriu que desempenhos em leitura ematemáticas, tanto no terceiro como no quinto ano da escola primária, são sistematicamente mais altos nas escolas particulares que nas públicas, e mais baixos ainda nas escolas indígenas. Seu estudo também mostrou, porém, fraco desempenho para todos os alunos, já que, no máximo $50 \%$ alcançaram os padrões nacionaise, entre os al unos indígenas, tal proporção variou de $5 \%$ a $9 \%$ dos padrões esperados.

As fortes condições diferenciais e o impacto concomitanteentre escol as públicas e particulares não são tratados como tema político de maior importância na região latino-americana, deparando-secomo silêncio e são prontamente evitadas.
A natureza bifurcada da escolaridade pública/privada simplesmente não é mencionada em quaisquer discussões oficiais quanto à eqüidadeda educação.

\section{A distribuição desigual deprofessores}

Como muitos professores consi deram mais vantajoso e confortável morar em regiões urbanas queemáreas rurais, muitos não economizam esforços para evitar servir no campo. O uso de contatos pessoais em posições educacionais superiores permite a al guns professores não serem transferidos para áreas rurais, tendo por resultado o fato de que os professores que vão para as regi ões rurais serem aqueles mais novos e inexperientes, ou com treinamento formal limi tado. Há grande variação quanto à quantidade de professores treinados entre os países; por exemplo, o Peru tem uma proporção muito mais alta de professores credenciados que o Brasil. No entanto, as áreas rurais de ambos os países - e, deforma geral, em toda a América Latina - têm muito mai or probabilidadedeterem professores inexperientes ou menos preparados.

Comparações entretipos de escol as no México, por nível deescolaridadedos professores, demonstram que, enquanto nas escolas urbanas de classe média cerca de $1,11 \%$ dos professores possuem nove anos ou menos de escol aridade, as escolas indígenas têm $20,9 \%$ dos professores nessa categoria. Ao contrário, $54 \%$ dos professores na escol a urbana de classe média têm 16 ou mais anos de escolaridade, em contraste com apenas 2,3\% dos professores na mesma categoria em escolas indígenas, e 24\% em escolas rurais marginais. Deve-se acrescentar, ai nda, a essas tristes condições ofato dequeescolas indígenas erurais marginais, em contrastecom escol as urbanas de classe média, escol as urbanas margi nais eescol as rurais desenvolvidas, todas terem acesso limitado a um di retor detempo integral $(5 \%$ em escolas rurais marginais e $20 \%$ em escolas indígenas) (Schmel kes, 2000).

Muitas professoras evitam trabal har em áreas rurais. A distribuição exata deprofessores por sexo e local de serviço não é conhecida, mas, generalizando-secom baseem evidências testemunhais e naquilo que já se estudou em outras partes do mundo, as professoras mais bem treinadas conseguem 
permanecer em regiões urbanas, enquanto aquel as que se submetem a serviço rural são menos treinadas, ou então, muitos professores rurais são do sexo masculino, proporci onando model os ocupaci onais limitados para as meninas.

As desigual dades em educação surgem da al ocação de recursos financei ros emateriais. Para começar, sabe-se bem que escol as particul ares pagam mel hor que escolas públicas, assim, um número de professores mais qualificados se transfere para as esferas mais recompensadoras. Além disso, os salários de professores da escola pública têm sofrido um decréscimo como passar do tempo. Um estudo dentre professores argentinos constatou que, entre 1980 e 1988, seus salários foram reduzidos à metade, em termos de poder de compra (Vior, 2001). Esseestudo também descobriu que professores recebem seus salários em atraso e já chegaram a ser pagos com bônus, válidos apenas na província onde foram emitidos. Estatísticas para o Peru indicam que os salários de professores e de diretores em escol as públicas sofreram decréscimos de 45\%, entre 1990 e 1996 (Iguiñiz; Dueñas, 1989), criando situações de considerável penúria econômica e a necessidade de que os professores assumam diversos empregos para poder sobreviver.

Fenômeno recentena Argentina, eem muitos outros países na região latino-americana, éa emergência de um setor "empobrecido", composto por um segmento da classe média, cujos rendimentos caíram e os colocaram abaixo da linha de pobreza. Vior (2001) observa que muitos professores argentinos podem ser local izados nesse setor. Como um ampl o número de professores da educação primária é de mulheres - 77\% para a América Latina eo Caribe (Unesco, 1995) - , esse fenômeno tem claras fei ções dediscriminação sexual.

\section{A distribuição desigual de recursos materiais}

Um estudo feito por Schmelkes e outros (1996), quanto às condições infraestruturais da escola num estado pobredo México, descobriu, demaneira nada surpreendente, que o acesso a instal ações básicas, tais como água de beber, latrinas, pátios derecreio, era bem maior em escolas servindo às classes médias urbanas do que nas escolas rurais marginaiseindígenas. Um padrão similar emergiu para condições nas salas de aula e na disponi bilidade de livros.

Usando uma amostragem ampla dealunos para os padrões latino-americanos, Cervini (2002) analisou o impacto de variáveis, tais como o capital econômico esocial sobre o desempenho de al unos urbanos, na sétima série do primeiro grau, na Argentina. Considerou também as condições da infra-estrutura da sala de aula e o tipo de escola. As descobertas de Cervini revelaram al guns achados esperados: o capital social e econômico das famílias afetou o desempenho cognitivo dos alunos. Mas, eletambém descobriu que, embora o desempenho diferencial do estudante tenha sido influenciado pel as condições da família, o contexto socioeconômico da escola teve um impacto ainda mai or sobre o desempenho do al uno - fato que reflete as condições de siguais das escolas e suas conseqüências discerníveis e independentes sobre o aprendizado.

Desigual como seja a escola, permane ce o fato de que a escolari dade é distribuída mais igual mente que as rendas. Isso vem sendo observado no caso do México (Martínez, 2002) etem probabilidades iguais de seconfirmar no resto dos países latinoamericanos.

\section{O efeito combinado de classe social e sexo}

A natureza da sociedade classificada por sexos causa um acesso desigual à escolaridade e aos seus benefícios entre meninos e meninas. O impacto negativo do sexo para as meninas é aumentado, quando el as pertencem a famílias de baixa renda. Evidências empíricas importantes sobre como a classesocial (conforme representado pela renda familiar) e sexo podem prejudi car a capaci dade da pessoa em freqüentar a escola provém de dados da Pesquisa DemográficaedeSaúde(PDS), coletadosem diversos países em desenvol vimento, entre 1994 e $2001 .^{5}$ Isso representa uma amostra de 45 em 117 países, ondeo PDS foi coletado. Embora nem todos os países estejam re presentados na amostra, tai s dados, diferindo de dados educacionais baseados em fontes administrativas coletadas pela Unesco, incluem a medida da renda familiar. Usando

\footnotetext{
5 AsPesquisas Demográficasede Saúdesão coletadas por umafirma particular, a Macro International, sob um contrato delonga duração comaUsaid. Essas pesquisas têm a reputação de produzir dados confiáveis, dedomicíliosnacional mente representativos, $e$ amostras delargaescalaquanto à demografia esaúde. Tais da dos são col etados, primariamente, para programas nacionaisdesaúdeeplanejamentofa miliar, mas incluem perguntas sobrefreqüênciaescolar dascrianças em cada domicílio. As perguntasreferentesàescolasão feitas a adul tos identificados como o chefe dafamília, esuas respostas podem ou não refle tir acuradamentea real participação dacriançana escola.
} 
o índiceFilmer-Pritchett paraa rendafamiliar (2000), este conjunto de dados em particular identificou sendo de baixo SES os alunos cujas famílias pertencem aos $40 \%$ da população com rendas familiares mai s baixas eidentificou como deal to SES os al unos cujas famílias pertencem aos $20 \%$ com maiores índices de renda familiar, em seus respectivos países. Os dados das tabelas que se seguem apresentam médias ponderadas por região (mantendo sob controle, portanto, as di ferenças no tamanho das populações).

Tabela 1 - Taxas de Assistência à Escola nas Regiões em Desenvolvimento, segundo Sexo, Faixa Etária e Nível Socioeconômico. Dados de 1990-2000 (percentagens ponderadas pela população nacional)

\begin{tabular}{|c|c|c|c|c|c|c|c|c|c|c|c|c|c|}
\hline \multirow{3}{*}{$\begin{array}{l}\text { Nível socio- } \\
\text { econômico } \\
\text { Região }\end{array}$} & \multirow[b]{3}{*}{$\begin{array}{l}\text { No. de } \\
\text { Países } \\
\text { Pesqui- } \\
\text { sados }\end{array}$} & \multicolumn{4}{|c|}{ Faixa Etária 10-14 } & \multicolumn{4}{|c|}{ Faixa Etária 15-19 } & \multicolumn{4}{|c|}{ Faixa Etária 20-24 } \\
\hline & & \multicolumn{2}{|c|}{ Alto } & \multicolumn{2}{|c|}{ Baixo } & \multicolumn{2}{|c|}{ Alto } & \multicolumn{2}{|c|}{ Baixo } & \multicolumn{2}{|c|}{ Alto } & \multicolumn{2}{|c|}{ Baixo } \\
\hline & & : & : & 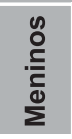 & 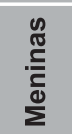 & $\frac{\text { : }}{\stackrel{0}{c}}$ & 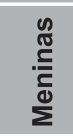 & $\frac{\text { : }}{\stackrel{c}{\frac{c}{c}}}$ & 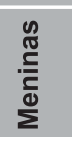 & $\frac{\text { o }}{\stackrel{c}{c}}$ & $\sum_{\substack{\frac{0}{c} \\
\frac{0}{c}}}^{\frac{0}{2}}$ & $\frac{\stackrel{0}{\circ}}{\stackrel{c}{c}}$ & 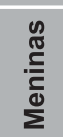 \\
\hline $\begin{array}{l}\text { África Oriental/ } \\
\text { Meridional }\end{array}$ & 13 & 87.5 & 82.4 & 60.7 & 54.5 & 57.6 & 42.9 & 39.6 & 22.3 & 20.2 & 10.7 & 9.1 & 2.3 \\
\hline $\begin{array}{l}\text { África Ocidental/ } \\
\text { Central }\end{array}$ & 13 & 86.6 & 79.8 & 46.7 & 38.7 & 67.3 & 53.0 & 31.0 & 18.1 & 40.1 & 25.9 & 13.2 & 4.8 \\
\hline Oriente Médio & 4 & 93.5 & 88.9 & 71.0 & 51.4 & 61.8 & 60.3 & 36.0 & 21.6 & 27.7 & 20.4 & 10.3 & 3.3 \\
\hline $\begin{array}{l}\text { Ásia Centro- } \\
\text { Meridional/ } \\
\text { Centro-Oriental }\end{array}$ & 7 & 90.7 & 88.1 & 72.5 & 66.0 & 67.4 & 58.0 & 32.1 & 21.9 & 32.0 & 20.3 & 8.0 & 4.1 \\
\hline $\begin{array}{l}\text { Caribe/América } \\
\text { Central }\end{array}$ & 4 & 96.3 & 92.6 & 72.7 & 70.4 & 81.0 & 74.0 & 39.4 & 29.7 & 50.2 & 43.1 & 9.6 & 6.3 \\
\hline América do Sul & 4 & 98.1 & 97.0 & 88.2 & 88.8 & 73.2 & 72.8 & 48.2 & 48.5 & 31.9 & 36.9 & 12.6 & 13.5 \\
\hline
\end{tabular}

A Tabela 1 apresenta comparação nacional cruzada, mostrando a média de freqüência escolar decomposta em três variáveis: sexo, renda familiar (alta e baixa) e faixa etária. São consideradas três faixas etárias, 10-14, 15-19 e20-24. Embora o autor deste trabal ho não tenha sel ecionado os agrupamentos por idade, eles têm significado teórico, já que, aos 15 anos, muitas moças já entram na puberdade e, assim, considera-se que corram riscos sexuais - o que, por preocupação dos pais, seria um dos fatores quelevariam ao reduzido índice de matrícul as para meninas, e, porque, nessa idade, espera-se que el as contribuam com uma fatia mai or dos trabal hos domésticos. Por volta dos 20 anos, em muitos países, as moças começam a casar-see, portanto, podemos razoavel mente inferir que isso afetará sua disponibilidade para os estudos.

A Tabela 1, em congruência com as estatísticas da Unesco, demonstra quecertas regiões oferecem mel hores oportunidades educacionais que outras. Assim, na América Latina, meninas entre as idades de 1024 anos sofrem uma desvantagem nas matrículas escolares, secomparadas aos meninos, a despeito da classe social ; assim mesmo, essa desvantagem é muito menor do que em outras regiões em desenvol vi mento. Em nível de educação primária e nos primeiros anos da educação secundária (capturados pela faixa etária 10-14 anos), as diferenças mais marcantes de acesso por sexo estão no Oriente Médio e na África Ocidental. O Caribe/América Central e América do Sul chegam bem mais perto da educação primária universal do que as demais regiões, significando, essencialmente, que se aproximam da paridade. O grau deacesso diminui grandemente dentro da faixa $15-19$, com, no máximo, $70 \%$ de matrículas nesse nível (também, no caso do Caribe eAmérica Latina). Dentro do grupo etário 20-24, o grau de acesso educacional 
torna-seainda mais limitado. Tal decréscimo na taxa de matrícula, à medida que os al unos vão ficando mais vel hos, é verdadei ro tanto para moças como para rapazes, mas émais marcado entre as moças eentre os pobres.

As Tabel as de 2 a 4 examinamo impacto que têm o sexo e a classe social (representados pela renda familiar) no acesso à educação. Usando-se os dados da Tabela 2 efracionando-se por rendafamiliar, as tabelas comparam, primeiramente, as condições das meninas com a dos meninos em famílias pobres (Coluna 1) e as condições das meninas com a dos meninos em famílias ricas (Col una 2); a seguir, as tabel as comparam as condições das meninas em associação à renda familiar (Coluna 3), com as condições dos meninos atribuíveis à renda familiar (Coluna 4). Essas tabelas mostram a desvantagem, em pontos percentuais, devido ao sexo (essa diferença foi computada através do uso de ponderação GPI, comparando a freqüência demeninas à de meninos, partindo-se da presunção que estes representam 100). As col unas 3 e 4 tomam a situação dapessoaricacomo o referente. Quanto mais baixa as diferenças de pontos percentuais para os dois grupos, mais próximos estão da paridade.

Tabela 2 - Desventagem da M enina, segundo o Nível Socioeconômico e os Efeitos Combinados devido ao Gênero e ao Nível Socioeconômico em Diferenças Percentuais, Faixa Etária 10-14 anos - Dados de 1990-2000

\begin{tabular}{|l|c|c|c|c|}
\hline \multicolumn{1}{|c|}{ Região } & $\begin{array}{c}\text { Desvantagem da } \\
\text { Menina de Nível } \\
\text { Socioeconômico } \\
\text { Baixo }\end{array}$ & $\begin{array}{c}\text { Desvantagem da } \\
\text { Menina de Nível } \\
\text { Socioeconômico } \\
\text { Alto }\end{array}$ & $\begin{array}{c}\text { Alto } \\
\text { Desvantagem da } \\
\text { Menina devido } \\
\text { ao Nível } \\
\text { Socioeconômico }\end{array}$ & $\begin{array}{c}\text { Desvantagem do } \\
\text { Menino devido } \\
\text { ao Nível }\end{array}$ \\
$\begin{array}{l}\text { África Oriental } \\
\text { /Meridional }\end{array}$ & 10 & 6 & 34 & 21 \\
\hline $\begin{array}{l}\text { África Ocidental } \\
\text { /Central }\end{array}$ & 17 & 8 & 52 & 46 \\
\hline $\begin{array}{l}\text { Oriente Médio } \\
\text { Śsia Centro-Meridional }\end{array}$ & 28 & 5 & 42 & 24 \\
\hline /Centro-Oriental & 8 & 3 & 25 & 20 \\
\hline $\begin{array}{l}\text { Caribe/América } \\
\text { Central }\end{array}$ & 3 & 4 & 24 & 25 \\
\hline América do Sul & 1 & 1 & 9 & 10 \\
\hline
\end{tabular}

Tabela 2 - Desventagem da Menina segundo o Nível Socioeconômico e os Efeitos Combinados devido ao Gênero e ao Nível Socioeconômico em Diferenças Percentuais, Faixa Etária 15-19 anos - Dados de 1990-2000

\begin{tabular}{|l|c|c|c|c|}
\hline \multicolumn{1}{|c|}{ Região } & $\begin{array}{c}\text { Desvantagem da } \\
\text { Menina de Nível } \\
\text { Socioeconômico } \\
\text { Baixo }\end{array}$ & $\begin{array}{c}\text { 年esvantagem da } \\
\text { Menina de Nível } \\
\text { Socioeconômico } \\
\text { Alto }\end{array}$ & $\begin{array}{c}\text { Desvantagem da } \\
\text { Menina devido } \\
\text { ao Nível } \\
\text { Socioeconômico }\end{array}$ & $\begin{array}{c}\text { Desvantagem do } \\
\text { Menino devido } \\
\text { ao Nível } \\
\text { Socioeconômico }\end{array}$ \\
\hline $\begin{array}{l}\text { África Oriental } \\
\text { Meridional }\end{array}$ & 46 & 26 & 48 & 31 \\
\hline $\begin{array}{l}\text { África Ocidental } \\
\text { /Central }\end{array}$ & 42 & 21 & 64 & 54 \\
\hline $\begin{array}{l}\text { Oriente Médio } \\
\text { Ásia Centro-Meridional }\end{array}$ & 40 & 13 & 64 & 52 \\
\hline /Centro-Oriental & 32 & 14 & 62 & 52 \\
\hline $\begin{array}{l}\text { Caribe/América } \\
\text { Central }\end{array}$ & 6 & 8 & 60 & 55 \\
\hline América do Sul & 0 & 1 & 33 & 34 \\
\hline
\end{tabular}


Tabela 2 - Desventagem da Menina segundo o Nível Socioeconômico e os Efeitos Combinados devido ao Gênero e ao Nível Socioeconômico em Diferenças Percentuais, Faixa Etária 20-24 anos - Dados de 1990-2000

\begin{tabular}{|c|c|c|c|c|}
\hline Região & $\begin{array}{c}\text { Desvantagem da } \\
\text { Menina de Nível } \\
\text { Socioeconômico } \\
\text { Baixo }\end{array}$ & $\begin{array}{c}\text { Desvantagem da } \\
\text { Menina de Nível } \\
\text { Socioeconômico } \\
\text { Alto }\end{array}$ & $\begin{array}{c}\text { Desvantagem da } \\
\text { Menina devido } \\
\text { ao Nível } \\
\text { Socioeconômico }\end{array}$ & $\begin{array}{c}\text { Desvantagem do } \\
\text { Menino devido } \\
\text { ao Nível } \\
\text { Socioeconômico }\end{array}$ \\
\hline $\begin{array}{l}\text { África Oriental } \\
\text { /Meridional }\end{array}$ & 75 & 47 & 79 & 55 \\
\hline $\begin{array}{l}\text { África Ocidental } \\
\text { /Central }\end{array}$ & 64 & 36 & 82 & 67 \\
\hline Oriente Médio & 68 & 26 & 84 & 63 \\
\hline $\begin{array}{l}\text { Ásia Centro-Meridional } \\
\text { /Centro-Oriental }\end{array}$ & 49 & 36 & 80 & 75 \\
\hline $\begin{array}{l}\text { Caribe/América } \\
\text { Central }\end{array}$ & 34 & 14 & 85 & 81 \\
\hline América do Sul & +1 & +2 & 64 & 61 \\
\hline
\end{tabular}

Nafaixa etária de 10-14, deacordo com a Tabela 2, a desvantagem de ser menina é sentidamais fortementenas famílias pobres (primeira coluna da tabela), ondeas meninas de baixa renda podem se ver em desvantagem em relação aos meninos pobres atéem 28 pontos, como aconteceno Oriente Médio. A desvantagem de ser mulher éatenuada pela riqueza dos pais, assim, em casas mais ricas, as meninas demonstram menor desvantagem nas matrícul as educa cionais, comparadas aos meninos (segunda coluna da tabela), uma desvantagem que chega, no máximo, a 8 pontos, como no caso da África Ocidental.

A Tabela 2 também mostra que, na faixa dos 10-14, a diferença entremeninas de famílias pobres ou ricas é forte (terceira coluna da tabela). Isso demonstra que a combinação de ser mulher eviver em famílias na pobreza leva a uma desvantagem educacional capaz de chegar ao pico de 52 pontos, na África Ocidental ou Central, e tão baixa quanto 9 pontos, na América do Sul. Esse "baixo" de nove pontos na Amé rica do Sul é interessante, pois essa éuma região que, em estatísticas agregadas, pareceter al cançado a paridade no nível da escola primária (ver Tabela 1).

Nas idades de 15-19, de acordo com a Tabela 3, as meninas em famílias pobres sofrem mais desvantagens que os meninos, chegando a um nível de desvantagem de 46 pontos, na região da África Oriental e do Sul. Meninas em famílias ricas também seacham em desvantagem perante seus pares masculinos, chegando a uma desvantagem tão el evada quanto 26 pontos de porcentagem, também na África Oriental e do Sul. A desvantagem nessa idade ainda se agrava mais de acordo com a renda familiar. Assim, as diferenças entre meninas ricas e pobres chegam a uma disparidade de 64 pontos, como é o caso na África Central e Ocidental eno Oriente Médio (Coluna 3). Nas idades de 20-24, de acordo com a Tabela 4, a diferença entre meninas de famílias pobres e ricas dispara para cerca de 20 pontos, comparada ao grupo etário entre 15-19, indicando uma diferença tão al ta quanto 85 pontos, no caso do Caribe/A mérica Central, seguido deperto pela do Oriente Médio (84 pontos).

As Tabel as 2 a 4 revelam as persistentes assi metrias no acesso educacional devidas ao sexo, tanto quanto à classe social . Os dados dão fortes evidências quanto ao efeito somado de sexo e classe social, tão bem quanto ao fato de que sua conjunção prejudi ca severamenteas chances educacionais das moças pobres. Considerando-se todas as possibilidades permitidas pelos dados, apenas em duas regi ões (Caribe/ América Central eAmérica do Sul, para a faixa etária 10-14 anos, ea América do Sul para o grupo entre 15-19 anos), a desvantagem de ser pobree do sexo masculino (Coluna 4) seria mai or do que a de ser pobree do sexo feminino (Coluna 3). Além do mais, em ambas as regiões, a diferença a favor das 
meninas chega meramentea um ponto. Sua vantagem nafaixa dos 10-14 anos é produzida principal mentepelos países do Caribe, onde as mel hores condições de educação para as meninas devem-se, em parte, às famílias matriarcais, oriundas da antiga experiência com a escravatura, conforme muitos cientistas sociais observam ser o caso no Caribe. A desvantagem para os rapazes, comparados às meninas, na América do Sul, provavel mente se deve ao emprego de meninos em ocupações tais como construção e transporte, que requerem menos treinamento educacional formal .

As desvantagens experimentadas pelos meninos pobres, se comparados a meninos ricos, em todo o mundo em desenvolvimento (Coluna 4), é menor que aquela experimentada pel as meninas ricas (CoI una 3). Esses dados podem ser considerados como capazes de oferecer evidências substanciais e atuai s de que as diferenças de sexo operam como um índice social mais discriminatório, no tocanteà participação na educação e que a combinação de pertencer a uma bai xa classe social e ser do sexo feminino apresenta maiores obstácul os à mobilidade social através da educação, especial menteà educação mais elevada. A revelação muito interessante contida nesses dados éque, embora a América Latina, deuma perspectiva econômica, seja tão desigual, mais meninas que meninos freqüentam a escola. Por outro lado, também é verdade que, na América Latina, como no restante do mundo, meninas em famíl ias pobres sofrem mai ores desvantagens, tanto diante das meni nas em famílias ricas como perante os meninos em famílias pobres.

\section{Políticas públicas distributivas}

A té uma década atrás havia um consenso de queo Estado deveria intervir nos assuntos nacionais, não só para promover o crescimento econômico, mas também para os propósitos de distribuição da justiça. Como observa Sloan (1984), a redistribuição da riqueza é, tal vez, a ação mais importante que o estado pode fazer em direção à justiça social. No entanto, como essa medi da seria grandementecontroversa, formas menos diretas de distribuição de rendas são geral mentetentadas.
Taxação, uma estratégia indireta para a redistribuição, é contestada, de maneira geral , não apenas no momento da taxação, mas, também - e primariamente - no instante de se fazer cumprir as regul amentações. Uma enorme evasão de impostos caracteriza a região. Além disso, em clima de constantes incentivos para investimentos internacionais, muitas isenções fiscais Ihes são dadas, tendo, por resultado final, o fato de muitos países terem capaci dade muito baixa de recolher impostos. A taxação representa uma pequena proporção de seus PIB, variando de $12 \%$ no Peru e $21 \%$ no Chile, a 30\% no Brasil, comparados a cerca de 40\%-50\% entre países da União Européia. A maior parte da renda oriunda dos impostos, necessária para os orçamentos nacionais, origina-se em taxas de consumo, o quetorna essa forma al tamenteregressiva para as classes sociais pobres.

A distribuição de riquezas e de rendas através da educação éfraca, pois a escolaridade representa uma distribuição distante e muito indireta de rendas. A educação, diferindo das reformas urbana eagrária, não tira os bens materiais de um indivíduo para dar a outra pessoa. Assim, as políticas de distribuição através do acesso educacional são preferidas pel os governos e bem aceitas pela população em geral. A maneira de se fazer política, em sua mai oria, na América Latina, émuitas vezes caracterizada, por um lado, por grandes aspirações utópicas e retóricas e, por outro, pela implementação seletiva e por conta-gotas (Sloan, 1984). Muitos indivíduos e grupos recebem promessas de educação, previdência social, programas de saúde, e até de terras, mas apenas números muito limitados real mente recebem tais benefícios.

As metas educacionais atuais para a região, conformerefletidas nos A cordos de Educação da Reunião de Cúpula das Amé ricas, procuram "proporcionar acesso universal à conclusão de uma educação de qualidade para $100 \%$ das crianças até o ano 2010 " e "proporcionar acesso pelo menos a 75\% dos jovens, a uma educação secundária de qualidade, com uma porcentagem mai or dejovens que completem a educação secundária até 2010" (citados em Puryear; Alvarez, 2000, p. 1). A consecução dessas metas será facilitada por empréstimos do Banco Inter-Americano de Desenvol vimento e do Banco Mundial, além de diversas organizações bi laterais deajuda. Ainda resta 
ver até que ponto os planos nacionais de ação irão prosseguir com base em critérios de igualdadee eqüidade, procurando atender às crianças pobres, rurais eindígenas.

O principal motivo, pelo qual poucos conseguiram beneficiar-se das políticas públicas no passado, é que tais políticas não visavam a todos os necessitados, mas sim sel ecionavam um número muito limitado de beneficiados. E, como os potenciais beneficiários mais bem educados e mais bem integrados social mente tendem a saber mais sobre os benefícios em potencial, foram eles os que os reivindicaram e os receberam. U ma conseqüência paradoxal disso éque as políticas reduzidas de distribuição termi nam por reforçar a estratificação social, em vez de corrigilas (Sloan, 1984).

O conjunto mais abrangente de políticas públicas visando à redução de desigualdades, através da distribuição deriquezas, ocorreu em Cuba. Embora haja severos limites à liberdade política naquel e país, há mais justiça social que em qual quer outro país da América Latina, haja vista haver menos desemprego, subemprego, analfabetismo, desnutrição e doenças, e menos favelas que em qual quer outra nação latinoamericana. O bem-estar social em Cuba pareceser correlato ao al canceeducacional. Um estudo recente(Orealc, 1998), comparando 13 países latino-americanos, em termos de desempenho nos terceiros e quartos anos da escola primária, nas áreas dematemática elinguagem, descobriu queCuba consistentemente excedeu o desempenho de todos os outros países latino-americanos (por uma média de desvio-padrão um sobreo país mais próximo). ${ }^{6}$ Entreas variáveis quese descobriu estarem associadas ao al to desempenho nessa comparação cruzada nacional , estava a formação degrupos deal unos com habilidades mistas, al go mui to facilitado em países ondenão haja fortes distinções sociais.

\section{Medidas compensatórias}

Um meio direto para combater as desigual dades sociais em geral eas diferenças na educação, em particular, ocorre através da formulação de políticas compensatórias, focalizando-se nos grupos da população em desvantagem.

Dentre os países latino-americanos, o México e o Brasil distinguem-se por intervenções em larga escala. O México tem investido substancialmente na educação compensatória para os setores mais pobres, residindo em áreas rurais. O Programa para Abatir el Rezago Educativo (Pare), financiado por um empréstimo deUS $\$ 200$ milhões do Banco Mundial, com a duração de quatro anos, procurou incrementar a qualidade e a eficiência das escolas primárias rurais, através da melhoria da qualidade da escola, aprimorando o treinamento de professores, livros-texto, suprimentos educacionais, bibliotecas, supervisão eincentivos aos professores. O Programa Nacional de Educación, Salud y Alimentación (Progresa) foi iniciado em 1998 eainda está em efeito, mas agora sob o nome de "Oportunidades". Como Progresa, o programa investiu substanciosa importância de recursos nacionais - cerca deUS\$800 milhões, em 1999 - em diversas intervenções sociais, uma das quais focal izava-se na educação. ${ }^{7}$

O Progresa procurava mel horar a partici pação da escola por intermédio da intervenção nas condições no lar, através de estipêndios para estudantes, dados mediantetransferência em dinheiro vivo para as mães, transferência em dinhei ro para o consumo al imentar, eserviços bási cos de saúde para os membros de toda a família. Ambos os programas demonstraram progressos (al guns mais modestos que outros) em número dematrículas, permanência na escola etransição do primário ao secundário, al ém de taxas mais baixas de repetição. Nem o Pare enem o Progresa lograram sucesso em produzir ganhos cognitivos de monta. Isso nos diz que esforços para ajudar os pobres vão precisar de atenção mais complexa e duradoura. Outra lição tirada da experiência mexicana éo reconhecimento da necessidade de se produzir mais intervenções multilaterais, ou seja, intervir não apenas para aprimorar as condições da escola e a qualidade da educação oferecida por ela, mas, simultaneamente, trabal har na melhoria das características econômicas eculturais da família.

Esforços de menor porte estão sendo tentados em Honduras, no Chileeno Brasil. Em Honduras, o Programa de Subsídios às Famílias (Programa deAsignación Familiar), que segue o model o do Progresa, até certo ponto, proporciona um estipêndio mensal escol ar de cerca deUS $\$ 5$ por criança, a fim deencorajar as famílias muito pobres a enviar seus filhos à escol a primária. Políticas compensatórias no Chile, através do "900 
escolas", também merecem ser mencionadas. Esse esforço vem proporcionando assistência educacional adicional (treinamento de professores, materiais educacionais, aul as de reforço, pequenas bibliotecas escolares) nas escolas primárias mais fracas (assi midentificadas através da apl icação de testes padronizados nos al unos). No Brasil, o governo vem tentando subsídios às famíl ias rurais extremamentepobres (aquelas com rendimentos de menos de US $\$ 24$ por mês), através do programa Bolsa-Escola. Ele opera em $5 \%$ de todas as municipalidades brasileiras, proporcionando bolsas de cerca de US\$ 4 por criança matriculada. Relata-se que o Bolsa-Escola, durante seus quatro anos de vida, conse guiu mel horar o acesso à escola, a permanência na mesma eo aproveitamento acadêmico (Secretaria do Programa Nacional de Bolsa-Escola, 2002).

Uma vez que as mulheres jovens, em áreas rurais, experimentam uma séria desvantagem perante os rapazes, devendo-se, em geral, às suas responsabili dades domésticas, que exemplos existem de políticas públicas significativas a respeito de diferenças por sexo e educação? Dois países, apenas, implantaram tais políticas. O componente educacional do Progresa continha incentivos mais el evados para a participação de meninas do que de meninos nos três primeiros anos da educação secundária, cerca de US\$ 4 a mais por criança, numa bolsa de aproximadamenteUS $\$ 28$ por mês. Outra tentativa foi feita mediantesubsídios às meninas na escola primária, primeiramente em áreas rurais, estendendo-se depois às áreas urbanas, na Guatemala, um programa abrangendo cerca de $30 \mathrm{mil}$ meninas, no espaço de três anos, mas agora extinto. Não se sabe se esse programa foi avaliado; um programa-piloto, queo precedeu, real mente descobriu que as meninas que recebiam a bolsa tinham médias mais al tas de freqüência, promoção da primeira para a segunda série e conclusão do grau, queas estatísticas nacionais (Stromquiste outros, 2000). Descobriu-sequeos incentivos em dinheiro do Progresa ajudaram a retenção das meninas, mas não foram capazes de reduzir a brecha entre o abandono escolar entremeninas emeninos após a escola primária (Murphy-Graham, 2003).

Exceto pelo pequeno número de países acima mencionados, não foram implementadas outras políticas substanciais para reduzir as desigual dades educacionais na América Latina. Em geral, fica claro que políticas sociais limitam-se, tipicamente, aos grupos emmaior desvantagem, esão demagnitude tão pequena que não são capazes de resolver o problema da exclusão social. Conforme argumentam diversos observadores, tais políticas parecem ser adotadas para que se mantenham níveis mínimos de governabilidade, ou seja, para seevitar convulsões sociais (Vior, 2001; Sloan, 1984).

\section{0 futuro teimoso da desigualdade}

Há diversas condições e forças sociais na região tornando al tamente prováveis as perspectivas de reprodução e manutenção da desigual dade, inclusi veas desigual dades educacionais.

\section{Pobreza}

A degradação social eeconômicaécausada, em extensão considerável, pel o modelo de desenvolvimento econômico que assume um papel favorecendo as transações de mercado ea importância da industrial ização sobre todos os outros modos de produção. Esse model o apresenta um vício urbano, empiricamente demonstrado por extensos dados retirados do PDS, mostrando queáreas urbanas têm muito mel hor acesso aos serviços básicos, tais como água, esgotos e el etricidade (Hewett; Montgomery, 2001). ${ }^{8}$ A cesso a mais serviços de educação e de saúde se tornam possíveis nas cidades, o que serve de motivo ulterior para os pobres abandonarem as áreas rurais.

O Banco Mundial prevêum crescimento econômico muito pequeno para a região latino-americana, em 2003. Enquanto seespera queo PIB daÁsia Oriental cresça em $6 \%$, eo do Sul daÁsia em 5,4\%, calcula-seque o da América Latina - tão bem quanto da Europa Oriental - crescerá emapenas 1,8\%. É provável, portanto, que investimentos diretos estrangei ros continuem a ser dirigidos para a Ásia. O preço da matéria-prima- determinado pelos países industrial izados, com pouca margem demanobra para os países produtores - também afetaa América Latina. Deacordo com fontes do Banco Mundial, durante 2002 , os preços do café caíram em $8,8 \%$ eo do açúcar em $26,6 \%$, ambos importantes produtos deexportação da região.

\footnotetext{
Essesautores expressam preocupação dequeos esforços atuais para descentralizar o gover no possam deixar áreas rurais cadavez maismarginalizadas, já quepodemnão contar comfundossuficientes parainvestirem serviços básicose, por conseqüência, optar por privatizar tais senvicos, comascorrespondentes desigual dades sociais que isso vai gerar.
} 
Novas e contínuas expressões de pobreza estão causando sérios transtornos em muitos países. A Argentina, quejuntamente com o Uruguai, era considerada o país oferecendo o mel hor sistema educacional daAmérica Latina, atual menterelata que, naEscolaSecundária, menos da metade da população que deveria estar matricul ada de fato o está. Umestudo deExperton, em 1999 (citado em Vior, 2001), descobriu que entre 1991 e 1997 não houvequal quer crescimento de matrículas no ensino médio para o quintil de renda econômica mais baixa da Argentina.

\section{Racismo persistente}

Enquanto os especial istas na América Latina sentir-seiam muito mais confortáveis referindo-se ao conceito como póscolonialismo, umtermo maistangível seria racismo. As grandes diferenças de rendas são manifestação de grandes distinções de classe social, incluindo a negl igência espe cífica para com as populações indígenas, queforam partedas civilizações maia, asteca einca. Também negl igenciados são os grandes grupos de ascendência africana, particul armente no nordeste do Brasil . I deologias raciais prevalecentes consi deram o "Outro" com desprezo, desconsideração manifesta por falta de atenção aos problemas desses grupos. Esse racismo éexercido não só pel os brancos, mas também por muitos mestiços. É mínima a oferta educacional para as populações rurais, tanto de crianças como de adultos, e assim, conseqüentemente, o bai xo rendimento educacional é reproduzido através das gerações.

Também, no caso do Peru, um economista concluiu, após um estudo el aborado, que:

Uma transferência sel etiva de $5 \%$ da renda nacional, retirada do $1 \%$ do topo da população e dada ao primei ro quartil (mais pobre), iria reduzir as rendas no topo em cerca de $16 \%$, e dobraria a renda de um terço da população. Se a alternativa para a redistribuição fosse o crescimento, em um esforço para o desenvolvimento al tamente bem-sucedido, consistindo de um crescimento real sustentável de $3 \%$ por ano em todos os rendimentos, levar-seia 20 anos paraal cançar amesma mel horia para o terço inferior e muito mais tempo ainda, se descontarmos a espera envolvida(Sloan, 1984, p. 86, citando Webb).
Com muita freqüência nós nos referimos à "pobreza pertinaz" em nossa anál ise de condições econômicas e sociais, no entanto, a frase mais apropriada deveria ser "riqueza pertinaz". Embora não sendo uma transferência exorbitante, édifícil imaginar membros da classe branca superior se desfazendo desua riqueza para dála a um grupo grande de indígenas, mesmo sabendo que o resultado seria uma economia de meIhor funcionamento. No caso do Brasil, o atual presidente, Luiz Inácio Lula da Silva enfrenta a perspectiva de continuar com o status quo ou tentar uma reforma agrária como medi da redistributiva rápida. Dequalquer modo, eleterá deenfrentar muitatensão política.

\section{Filosofias econômicas e políticas neoliberais}

As tendências gl obais que fazem com quepolíticas públicas, ao mesmo tempo fracas e improváveis, sejam implementadas incluem posições econômicas e políticas equacionando a ação do estado com incompetência e corrupção, enquanto os resultados de mercado são considerados eficientes, transparentes e até mesmo democráticos. Esses princípios são largamente apoiados nos países do Norte eforam exportados para a América Latina, na qual reformas políticas vêm pedindo a liberação do comércio, privatização, a desregularização e um mínimo de seguridadesocial (Williamson, 1990). O neol iberal ismo aceita as desigual dades porque o crescimento depende de investimentos em capital físico, eo investimento depende de poupança, a poupança depende da concentração da riqueza limitada nas mãos das poucas pessoas que vão ter mais do que o suficiente sobrando das suas economias, após a satisfação de seus desejos de consumo (Sloan, 1984). Há pouca evidência de queo mercado funcione tão bem.

Não podemos discutir o impacto da pobreza sobre a educação na A mérica Latina e deixar de considerar as condições macroeconômi cas que têm deixado tantos países da região em tamanha penúria. Inquestionavel mente, as transações entreos países industrializados e emergentes vêm deteriorando, na perspectiva da ética social. Um estudo das desigual dades que medem esse conceito, em termos de taxas de pagamento eestruturas deganho, apenas no 
setor de manufatura, ${ }^{9}$ descobriu que, desde 1980, tem havido "um aumento extraordinário esistemático da desi gual dade" em todo o mundo (Gal braith, 2002, p. 23). Esse aumento foi atribuído não à incapacidade dos países em acompanhar as mudanças tecnol ógi cas acel eradas (o queseria o racional "educacional") mas simà dissol ução dos padrões Bretton Woods detaxas de câmbio fixas, mas ajustáveis, e da supervisão internacional dos fluxos de capital, da dívida externa e das políticas econômicas neol iberais, ea ausência de quai squer novas arquiteturas financei ras capazes de levar alguma ordem e proteção aos países fracos (Gal braith, 2002).

No período 1970-1999, pessoas em pobreza absoluta (vivendo com menos del dólar por dia), declinaram de 1,4 para 1,2 bilhão (Dikhanou; Ward, 2000). Contudo, o número de indivíduos que vivem com menos de 2 dólares por dia - ainda pessoas muito pobres - representa metade do mundo, naquilo que se tornou uma economia cada vez mais monetarizada. Alguns economistas começam a reconhecer queo crescimento econômico não parece ser a principal maneira de reduzir a pobreza (Dikhanou; Ward, 2000; Cepal , 2002), mas essas vozes discordantes se perdem nalouca corrida em direção às perspectivas tentadoras, mas não real izadas, da gl obal ização daeconomia.

De acordo com a Comissão Econômica da ONU para a América Latina e o Caribe, a economia gl obalizada da região vem se caracterizando por um processo de reconfiguração de seus setores econômicos, com uma redução no setor industrial , uma tendência na direção demai ores transações financeiras, uma clara ênfase na agroindústria para exportações, ena manutenção do setor demineração (Cepal , 2002). Essanova economia vai sebeneficiar deuma força de trabal ho altamenteeducada, masé pouco provável quesejam necessários grandes números de trabal hadores muito instruídos.

\section{Um ethos educacional apolítico}

A manutenção de desigualdades na soci edadee na educação está sendo facilitada pela expansão de idéias e práticas educacionais definindo a educação, em termos estritos, como uma incul cação de conhecimento quevisa tornar os países economicamente competitivos, equeenfatiza a avaliação do desempenho do al uno e do professor, em vez decuidar da provisão de recursos suficientes para se criar um ambiente educacional efetivo. Organizações internacionais de empréstimos e agências bilaterais influentes na regi ão estão patrocinando model os de descentralização que dão aos pais a opção de criar escolas públicas independentes ou de usar fundos públicos para matricular os fil hos em escolas particulares (através de versões de escolas autorizadas e de um programa de val es, respectivamente, primeiramentetentado nos Estados Unidos) (Krawczyk, 2002; Stromquist, 2003). Testes padronizados estão se tornando universais na região (Beneviste, 2002), enquanto mudanças na direção da previsi bilidade, eficiência esalários baseados em desempenho assumem maior importância. No entanto, recursos para equi pamentos, treinamento e salários de professores continuam em atraso. Vem sendo rel atado, na verdade, que durante a década de 90, "a única categoria de gastos [governamentais] que revelou aumentos substanciai s e padronizados foi aquela de serviços de débi to" (Jonakin, 2002, p. 24).

Educadores latino-americanos vêm observando queos programas de treinamento de professores estão se tornando mais técnicos, encaminhando-se na direção de cursos di dático-metodológi cos, e afastando-se de cursos voltados para as preocupações históricas, sociais, políticas e econômicas. No caso da Argentina, relata Vior (2001, p. $81)$, os planos atualmente em andamento consideram, com efeito, apenas dois cursos baseados nessas matérias, dessa forma "enfraquecendo, entreos professores, a função do conhecimento que promovea consciência social sobre as relações sociais e econômicas complexas do país, o sistema educacional esua própria prática. Através denormas central izadas, incluindo recompensas individuais visando ao desempenho dealunos em testes, os professores estão sendo empurrados para ambientes al tamentecompetitivos, quecondicionam suas rendas pessoais e seu status a desempenho específico de trabal ho (Brusilovsky; Vior, 1998). Isso não deixa lugar para reflexões e ação progressiva. Infelizmente, sob o cl ima apolítico e tecnocrático da reforma educacional de hoje, vozes críticas, quelevantam questões sobreo caminho na direção da modernização

\footnotetext{
9 Este projeto internacional de comparaçãomededesigual dades através do uso do ÍndiceTheil. Ao centralizar-se no setor de manufatura, esseíndicededesigual dade produz uma compre ensãomaisestreitadaeconomia por suavez, mais precisaqueas computaç̃es apresentadas pelo Banco Mundial (usando o conjuntodedadosDeiniger-Squire), quesereferemarendasfamilia resreunidas através depesquisas domiciliares, mas quesão consideradas, por diversoseconomistas, como não confiáveis dado asuavariada composição através dos países, assimcomo arandequantidadededados quefaltamparaperíodos-chave
} 
da educação e seu provável efeito negativo na eqüidade, são vistas como irrelevantes e indesejáveis (Stromquist, 2003).

Educação desigual também se produz através da fraca demanda da parte de pais pobres, que, em geral, não têm acesso a manobras políticas substanciais. A ausência de programas de educação de adultos, particularmenteaquel es de natureza socialmente transformadora, impossibilita o desenvol vimento de atitudes críticas que poderiam levar os pais a ver a educação sob uma nova luz e a fazer reivindicações por mais recursos e conteúdos e propósitos alternativos na escol arização. Além disso, as crescentes condições de desigual dade na região vêm produzindo uma demobil ização de grupos organizados e o enfraquecimento da influência dos sindicatos trabal histas - dois conjuntos de forças que podiam lutar pela expansão dos direitos de cidadania e mai or igual dadesocial (Oxhorn, 1998).

\section{Conclusões}

Com base em diversas evidências em nível de país, pude construir um retrato coerente, mas preocupante, que prometea contínua manutenção e reprodução das desigualdades na América Latina. Uma confluência de forças econômi cas, políticas e culturai s cria terreno sólido favorecendo o status quo. Com uma escolarização dealta categoria possível para as elites atra vés das escolas particulares, a educação pública constitui uma preocupação residual na política nacional. Como diversos educadores críticos observaram, a educação não pode ser livre ou igual, até onde as diferentes classes sociais tenham acesso a uma escolarização diferenciada, parte dela em uma qualidade muito maior do que aquela disponível ao restante da população. Um sistema educacional em separado eal tamente diferenciado não écondutor à solidari edade e nem, por conseqüência, à democracia.

Com freqüência se fazem, na América Latina, manifestações oficiais para mel horar edemocratizar a educação, mas a procura por evidências de ações implantadas e empenhadas revela poucas respostas sólidas. Alguns programas compensatórios estão a caminho na região, a fim delevar mais acesso e completamento à educação decrianças muito pobres, ainda assim tais esforços são limitados e esparsos, tanto em tempo quanto em recursos. Além disso, medidas tais como a descentralização no nível da escola e programas de bol sas para escolas particul ares-agora bastante preval ecentes na região - tendem a desafiar o conceito de educação pública como um bem comum, uma vez quepermitema organização depequenos grupos de pais para propósitos individuais ou especiais.

Sob idéias neol iberais - também bastantetangíveis naregião latino-americana- a educação évista como um meio de permi tir que a economia de mercado cresça esetorne eficiente, um meio desolucionar os problemas atribuídos àgl obal ização econômica, tal como o desemprego ea pobreza. Mas, se o mercado écausa de desigualdade política esocial, então isso contradiz o argumento de que a educação devefacilitar a expansão da economia de mercado (McLaren; Fahmandpur, 2002, citando Spring).

A democracia, eassim, a igual dade social , não podem ser al cançadas sem respeito e conhecimento do "Outro". Isso se desenrola em dois níveis. Respeito pel o "Outro" dentro de nosso próprio estado, no relacionamento entre classes sociais e grupos étnicos, evidentena boa vontade deseal ocar mais recursos para a escol arização pública, rural , em especial , e o respeito pel o "Outro" através de nossas frontei ras nacionais, no relacionamento Sul-Norte, manifestado na boa vontade deseconsentir queoutros partilhem mais igualmente nos preços da economia mundial.

\section{Referências bibliográficas}

BENVENISTE, Luis. The political structuration of assessment: Negotiating State power and legitimacy. Comparative Education Review (Resenha da Educação Comparativa), v. 46, n. 1, p. 89-118, 2002. 
BRUSILOVSKY, Silvia; SUSANA Vior. La universidad argentina en los '90: políticas, procesos, propuestas. Tempora, v. 1, p. 199-219, Jan./Dez. 1998.

CEPAL. Panorama Social de América Latina 1994. Santiago: Comisión Económica para América Latina, 1994.

Panorama Social de América Latina 2001-2002. Santiago: Comisión Económica para América Latina, 2002.

CERVINI, Rubén. Desigual dades en el logro académico y reproducción cultural en Argentina. Un model o detres niveles. Revista Mexicana de Investigación Educativa, v. 7, n. 16, 2002.

CHOSSUDOVSKY, Michel. Global poverty in thelate20th Century. Journal of International Affairs (Boletim de Assuntos Internacionais), v. 52, n. 1, 1998.

COLEMAN, James. The concept of equality of educational opportunity. Harvard Educational Review (Resenha Educacional de Harvard), v. 38, p. 7-22, 1968.

DIKHANOV, Yuri; WARD, Michael. Evolution of the global distribution of income in 1970-1999. Washington, D.C.: Banco Mundial, March 2002. Minuta.

FILMER, Deon; PRITCHETT, Lant. Estimating wealth effort without expenditure. Data or Tears: an Application of Education Enrollment in States of India. Washington, D.C.: Banco Mundial , Aug. 2000, minuta.

GALBRAITH, James K. A perfect crime: inequality in theage of globalization. Daedalus, v. 131, n. 1, p. 11-25, 2002.

HEWETT, Paul; MONTGOMERY, Mark. Poverty and public services in developing-country cities. Consel ho Populacional de Nova York: 2001. n. 154.

HORNBERGER, Nancy. Schooltime, classtime, and academic learningtimein rural highland puno, Peru. Anthropology \& Education Quarterly (Antropologia \& Educação Quadrimestral), v. 18, n. 3, p. 207-221, 1987.

IGUIÑIZ, Manuel; DUEÑAS, Claudia. Dos miradas a la gestión de la educación pública. Lima: TAREA, 1989.

JONAKIN, Jon. The Inter-American Development Bank's assessment of structural adjustment. questionable theory and pre-ordained policy. Canadian Journal of Latin American and Caribbean Studies (Boletim Canadense de Estudos Caribenhos e LatinoAmericanos), v. 26, n. 51, p. 49-81, 2002.

KABEER, Naila. Agency, Well-Being and Inequality: reflections on the gender dimensions of poverty. IDS Bulletin (Boletim do IDS), v. 27, n. 1, p. 11-21, 1996.

Tácticas y compromi sos: nexos entre género y pobreza. In: ARRIAGADA, Irma; TORRES, Carmen (Ed.). Género y pobreza. Nuevas dimensiones. Santiago: ISIS Internacional, 1998.

KRAWCZYK, Nora. La Reforma Educativa en América Latina desde la perspectiva de los organismos multilaterales. Revista Mexicana de Investigación Educativa, n. 16, 2002.

MARTÍNEZ RIZO, Felipe. Nueva visita al país de la desigualdad. La distribución de la escolaridad en México, 1970-2000. Revista Mexicana de Investigación Educativa, v. 7, n. 6, p. 415-443, set./dez. 2002.

MCLAREN, Peter; FARAHMANDPUR, Ramin. Freire, Marx, and the new imperialism: toward a revolutionary praxis. In: SLATER, Judith; FAIN, Stephen; ROSSATTO, Cesar (Ed.). The freirean legacy. Educating for social justice. Nova York: Peter Lang, 2002. p. 3756. 
MONTERO, Carmen; TOVAR, Teresa. Agenda abierta para la educación de las niñas rurales. Lima: CARE Peru, Instituto de Estudios Peruanos e Foro Educativo, 1999.

MURPHY-GRAHAM, Erin. Progresa/Case Study. Cambridge: GraduateSchool of Education, Universidade deHarvard, Feb. 2003. Minuta.

OECD. Investing in education. Analysis of the 1999 world education indicators. education and skills. Paris: OECD, 2000.

OREALC. First internacional comparative study of Language and Mathematics and associated factors. Santiago: Laboratorio Latinoamericano deEvaluación de la Cali idad de la Educación, Oficina Regional deEducación para la América Latina y el Caribe, 1998.

OXHORN, Phillip. Social inequality, civil society and the limits of citizenship in Latin America. Paper presented at the annual meeting of the Latin American Studies Association, Chicago, 24-26 setembro 1998.

PURYEAR, Jeffrey. International Education Statistics and Research Status and Problems. International Journal of Educational Development, v. 15, n. 1, p. 79-91, 1995.

PURYEAR, Jeffrey; ALVAREZ, Benjamin. Implementing the education agreements of the Santiago Summit. Working Paper Series. Coral Gables: TheDanteB. Fascell North-Sourth Center, Jun. 2000.

RODRÍGUEZ, Ernesto. A poyo financiero a los más pobres para facilitar las oportunidades educativas. Preal, v. 4, n. 12, p. 1-2, 2002.

SCHMELKES, Sylvia etal. The quality of primary education in Mexico: the case of Puebla. Paris: Instituto Internacional dePlanejamento Educacional , 1996.

SCHMELKES, Sylvia. Education and Indian peoples in Mexico: an example of policy failture. In: REIMERS, Fernando (Ed.). Unequal schools, unequal chances: the challenges of equal opportunity in the Americas. Cambridge: Harvard University Press, 2000. p. 319333.

PROGRAMA NACIONAL BOLSA ESCOLA. "Beca-Escuela" in Brasil. Preal, v. 4, n. 12, p. 3-4, 2002.

SLOAN, John W. Public policy in Latin America. A comparative survey. Pittsburgh: University of Pittsburgh Press, 1984.

STROMQUIST, Nelly; KLEES, Steven; MISKE, Shirley. Usaid efforts to expand and improve girls' primary education in Guatemala. In: CORTINA, Regina; STROMQUIST, Nelly (Ed.). Distant Alliances: promoting education for girls and women in Latin America. Nova York: RoutledgeFal mer, 2000. p. 239-260.

STROMQUIST, Nelly. Whilegender sleeps: Neoliberalism's impact on educational policies in Latin America. In: BALL, Stephen; FISCHMAN, Gustavo; GVIRTZ, Silvina (Ed.). Latin America's Educational hopscotch: understanding thelegacy of neo-liberal approaches to educational. Nova York: RoutledgeFalmer, 2003.

UIS. Trends in out-of-school population in 16 countries. Montreal : Instituto para Estatísticas da Educação/UNESCO, 2003. Minuta.

UNESCO. Dakar Framework for Action - Expanded commentary. Education for All: meeting our collective commitments. Paris: Unesco, A pril 2000.

Statistical Yearbook 1995. Paris: Unesco, 1995.

Statistical Yearbook 1999. Paris: Unesco, 1999. 
VIOR, Susana. Neoliberalismo y formación de docentes. Argentina 1989-1999. In: BAQUERO, Rute; BROILO, Cecilia (Ed.). Pesquisando e gestando outra escola: desafios contemporâneos. Sao Leopoldo: Unisinos, 2001.

WILLIAMSON, John. What Washington Means by policy reform. In: WILLIAMSON, John (Ed.). Latin American adjustment: how much has happened. Washington, D.C.: Instituto para a Economia Internacional, 1990.

Nelly Stromquist é professora titular do Programa de Educación Comparada da University of Southern Cal ifornia, Los Angel es, EUA, com área de concentração em temas que rel acionam o desenvol vimento educacional eo gênero, os quais são examinados por el a sob a perspectiva da sociologia crítica.

\section{Abstract Inequality as a way of life: education and social class in Latin America}

Inequality in education is regretted by the government and by the society. Despite this feeling, the differences in the quality and in the access continue without efficient reasoning because attached to this are: the division of schools into private and public and the decay of agrarian schools in relation to the number of hours spent in class activities; teachers training; and infrastructure. Recent regional statistics over the combined effect of social class and gender indicate that women, of any school-age and of any socioeconomic stratus, are in disadvantage in relation to school access when compared to men. The compensatory measures to diminish inequality are almost inexistent in the region. Other factors, including racism and supposedly non-political models of development, are strongly rooted to educational policies and even to the Latin American behavior.

Keywords: educational inequalities; social class; quality; poverty; compensatory policies; gender; racism.

Recebido em 15 dejaneiro de 2004.

A provado em 16 de março de 2004. 